\title{
PHYLOGENETIC RELATIONSHIPS OF THE SUBGENUS CERATOTROPIS BASED ON RANDOM AMPLIFIED POLYMORPHIC DNA
}

\author{
V.A. SUMANASINGHE ${ }^{1,2}$, N. TOMOOKA ${ }^{2}$ and S. FUKUOKA ${ }^{2}$ \\ ${ }^{1}$ Department of Agricultural Biology, Faculty of Agriculture, University of Peradeniya, \\ Peradeniya. \\ ${ }^{2}$ National Institute of Agrobiological Resources, Tsukuba - shi, Ibaraki - 305, Japan.
}

(Received: 14 March 1996; accepted: 07 March 1997)

\begin{abstract}
Random Amplified DNA Polymorphism (RAPD) was detected for 24 different accessions of 12 different species in the subgenus Ceratotropis of the genus Vigna. Of the 52 RAPDs generated with 8 decamer primers only one was monomorphic and 51 were polymorphic. Each accession could be distinguished from each other by at least a single RAPD fragment. The cluster analysis based on UPGMA identified 2 major clusters at $70 \%$ dissimilarity level representing the azuki and mungbean groups. The 4 accessions of the 3 species in the mungbean group were more divergent than the other 20 accessions of 9 species of the azuki group. $V$. reflexo-pilosa and $V$. glabrescens exhibited the closest affinity among the species. The results were in agreement with the reported analyses based on RFLPs and isozymes.
\end{abstract}

Key words: Ceratotropis, PCR, phylogeny, RAPD, Vigna.

\section{INTRODUCTION}

The subgenus Ceratotropis (Asian Vigna) is a morphologically homogeneous and specialized group of Asian origin. The taxonomic treatment of this group is confusing. Verdcourt, ${ }^{1}$ transferred the group from the genus Phaseolus to the genus Vigna. Mare'chal et al. ${ }^{2}$ followed Verdcourt and presented a monograph on the Phaseolus-Vigna complex and this has now become the most widely accepted taxonomic treatment on the Phaseolus-Vigna complex.

According to Maréchal et al. ${ }^{2}$, the subgenus Ceratotropis consists of 16 species which includes five cultivated crop species, i.e., mungbean (Vigna radiata), blackgram (V. mungo), moth bean (V. aconitifolia), rice bean ( $V$. umbellata) and azuki bean ( $V$. angularis). Maekawa ${ }^{3}$ suggested that Ceratotropis should be divided into two separate genera (Azukia and Rudua) on the basis of differences in seedling characters. Species within the genus Rudua show epigeal germination having a primary leaf with a very short petiole, while species belonging to the genus Azukia show hypogeal germination having a primary leaf with a long petiole. Although this concept has not been supported by further studies, it is convenient to use this concept in this study. The genus Rudua includes mungbean, blackgram and moth bean, while the genus Azukia contains rice bean and azuki bean as cultivated species. Therefore, the genus Rudua and the genus Azukia are hereafter referred to as "mungbean group" and "azuki group", respectively, in the present paper. The species of the "mungbean group" are 
distributed mainly in the Indian Subcontinent, while the species of the "azuki group" are found principally in East and Southeast Asia. Since the available number of specimens for the wild species in "azuki group" is so limited, suggestion was made ${ }^{2}$ that the taxonomic treatment of the wild species in the "azuki group" should be rearranged by further examination of the newly collected specimens. Recently, several wild species belonging to the "azuki group" were collected in Thailand, Japan and Malaysia by exploration. ${ }^{4-7}$

The objective of the present study was to apply RAPD (Random Amplified Polymorphic DNA) analysis in the species in the subgenus Ceratotropis to clarify the phylogenetic relationships among the species.

\section{METHODS AND MATERIALS}

Materials: All the plants analyzed were grown in a greenhouse at the National Institute of Agrobiological Resources, Tsukuba, Japan. Forty five accessions involving at least two accessions each from 20 species both from azuki and mungbean groups were included at the DNA isolation stage and 24 selected accessions from 12 species at the RAPD detection. The young tender leaves harvested from mainly 1-2 week old seedlings or from somewhat mature plants were used. The species, accessions and their place of origin are given in Table 1.

Extraction of DNA: Two methods were adapted in DNA isolation. At the inception, isolation of DNA in larger quantities was attempted based on Murray \& Thompson. ${ }^{8}$ Tender leaves (about $8 \mathrm{~g}$ of fresh weight) were collected in an ice container, cut into small pieces, frozen in liquid nitrogen and stored at $-80^{\circ} \mathrm{C}$. They were freeze dried for $48 \mathrm{~h}$ and ground to a fine powder using Cyclotec sample mill grinder.

The powdered leaf sample was transferred into a $50 \mathrm{ml}$ vial and $15 \mathrm{ml}$ of hot 1x CTAB buffer ( $1 \%$ cetyltrimethyl ammonium bromide; $0.1 \%$ Tris- $\mathrm{HCl}, \mathrm{pH} 8.0$; $1.4 \mathrm{M}$ sodium chloride) was added into it and then placed in a water bath at $57^{\circ} \mathrm{C}$ for $30 \mathrm{~min}$. Proteins were separated into a heavier lower phase by centrifugation at $2500 \mathrm{rpm}$ for $15 \mathrm{~min}$ after mixing $10 \mathrm{ml}$ of 1 isoamyl alcohol : 24 chloroform $\mathrm{v} / \mathrm{v}$ solution. DNA was precipitated with an equivalent volume of precipitation buffer (1\% CTAB; 50mM Tris-HCl, pH 8.0; 10mM EDTA) and recovered by centrifugation at $2500 \mathrm{rpm}$ for $15 \mathrm{~min}$. The pellet was completely dissolved in $10 \mathrm{ml}$ of high salt-TE buffer (1M NaCl; $10 \mathrm{mM}$ Tris-HCl,pH $8.0 ; 1 \mathrm{mM}$ EDTA) at $57^{\circ} \mathrm{C}$ in a water bath for 3-4 h. DNA was re-precipitated with an equal volume of isopropanol after centrifugation again at $2500 \mathrm{rpm}$ for $10 \mathrm{~min}$ to remove undissolved contaminants and transferred carefully with a blunt-tipped disposable pipette into a $1.5 \mathrm{ml}$ effendorp vial. The pellet was washed with $2-3$ changes of $70 \%$ ethanol and stored at $4^{\circ} \mathrm{C}$ in a refrigerator in $0.1 \mathrm{xE}+100 \mathrm{x}$ RNase $(100 \mu \mathrm{g} / \mathrm{ml}$ RNase). 
Table 1: Accessions used in the experiment.

\begin{tabular}{|c|c|c|c|}
\hline ID No. & Species Name & Accession Name & Origin \\
\hline $\mathrm{C} 1-1$ & V. angularis var. angularis & Kyoto Dainagon & Japan \\
\hline $\mathrm{C} 1-2$ & " & 102 & $"$ \\
\hline $\mathrm{C} 2-1$ & V. angularis var nipponensis & Sendai & $"$ \\
\hline $\mathrm{C} 2-2$ & " & VA0001 & $"$ \\
\hline C3-1 & V. umbellata var. umbellata & $89-531$ & Nepal \\
\hline C3-2 & $"$ & NT9152 & Thailand \\
\hline Chan & $"$ & Chanta Buri & $"$ \\
\hline C4-1 & V. umbellata var. gracilis & $6-1-1$ & $"$ \\
\hline $\mathrm{C} 4-2$ & " & DKL & $"$ \\
\hline C5-1 & V. riukiuensis & Irio-5 & Japan \\
\hline $\mathrm{C} 5-2$ & $"$ & TNH 25277 & Taiwan \\
\hline C6-1 & V. nakashimae & Kankoku & Korea \\
\hline C6-2 & " & Ukushima & Japan \\
\hline C7-1 & $V$. minima var. minima & Fujieda & Taiwan \\
\hline $\mathrm{C} 7-2$ & $V$. minima subsp. gracilis & M27 & Malaysia \\
\hline C8-1 & $"$ & Species C & Thailand \\
\hline $\mathrm{C} 8-2$ & " & Somyot 23 & $"$ \\
\hline C9-1 & unidentified species & Species D & $"$ \\
\hline $\mathrm{C} 9-2$ & " & Somyot 20 & $"$ \\
\hline $\mathrm{C} 10$ & $V$. nepalensis & Nepalen & Nepal \\
\hline C11-1 & $V$. trinervia & M18 & Malaysia \\
\hline C11-2 & $"$ & NT9144 & Thailand \\
\hline M3 & $"$ & M3 & Malaysia \\
\hline M12 & $"$ & M12 & $"$ \\
\hline M36 & " & M36 & $"$ \\
\hline C12-1 & $V$ reflexo-pilosa & M23 & $"$ \\
\hline $\mathrm{C} 12-2$ & $"$ & Yona 5 & Japan \\
\hline $\mathrm{C} 13$ & V. glabrescens & V1160 & Philippines \\
\hline C14-1 & V. radiata var radiata & Tanegashima & Japan \\
\hline C14-2 & $"$ & 250007 & Iran \\
\hline C15-1 & V. radiata var. sublobata & TC1965 & India \\
\hline C15-2 & $"$ & TC1966 & Madagascar \\
\hline $\mathrm{C} 16-1$ & V. mungo var. mungo & Subsomotod & Thailand \\
\hline C16-4 & $"$ & $\mathrm{BC} 48$ & $"$ \\
\hline C17-1 & $V$. mungo var. silvestris & TC2211 & India \\
\hline $\mathrm{C} 17-2$ & $"$ & Somyot 5 & Thailand \\
\hline $\mathrm{C} 17-3$ & $"$ & TC2210 & India \\
\hline $\mathrm{C} 18$ & V. grandiflora & Species A & Thailand \\
\hline C19-1 & V. aconitifolia & Nilgiri & India \\
\hline C19-2 & " & 2752.5 & Pakistan \\
\hline C19-3 & $"$ & 2754.3 & $"$ \\
\hline C19-4 & " & 2762.2 & $"$ \\
\hline $\mathrm{C} 20-1$ & V. trilobata & $\mathrm{NI} 251$ & India \\
\hline $\mathrm{C} 20-2$ & $"$ & NI1030 & $"$ \\
\hline $\mathrm{C} 21$ & V. radiata var. setulosa & NI11135 & $"$ \\
\hline
\end{tabular}


However, since some accessions, at the dilution stage tend to produce smears and unclear bands, a small-scale modified method was attempted at DNA isolation. ${ }^{9}$ Mercapto ethanol $0.3 \%$ was added to $1 \mathrm{ml}$ of $2 \times$ CTAB buffer in order to remove phenolic contaminants. After isoamyl alcohol 1 : chloroform 24 extraction, DNA was precipitated using ammonium acetate : 6 ethanol v/v solution. Re-purification of DNA isolates was accomplished using phenolchloroform method. ${ }^{10}$ DNA concentration was estimated by the mini-gel method in comparison with $\lambda$-DNA of known concentrations.

PCR Runs: Polymerase chain reaction $(\mathrm{PCR})^{11}$ was performed in a polycarbonate microplate (Techne Hi-Temp 96) of $12 \times 8$ wells but using only the centermost 48 wells per run. Ing of template DNA was first placed at the bottom of the well and subsequently $8 \mu \mathrm{l}$ of premix consisting of $5.4 \mu \mathrm{l}$ of sterilized, demineralized distilled water, $1.0 \mu \mathrm{l}$ of $10 \mathrm{x}$ buffer $(10 \mathrm{mM}$ Tris- $\mathrm{HCl}, \mathrm{pH} 8.3 ; 50 \mathrm{mM} \mathrm{KCl}, 2 \mathrm{mM}$ $\mathrm{MgCl}_{2}, 0.001 \%(\mathrm{w} / \mathrm{v})$ gelatin, $0.2 \mathrm{mM}$ each of dATP, dCTP, dGTP, dTTP, $0.2 \mu \mathrm{l}$ of $25 \mathrm{mM}$ magnesium chloride, $2 \mu \mathrm{M}$ of random primer and 0.2 units of Taq DNA polymerase (Toyo, Japan) added and finally overlaid with a drop of mineral oil. The PCR apparatus (Techne PHC-Thermal Cycler) was programmed for 45 cycles each consisting of $93^{\circ} \mathrm{C}$ for $1 \mathrm{~min}, 35^{\circ} \mathrm{C}$ for $2 \mathrm{~min}$ and $72^{\circ} \mathrm{C}$ for $3 \mathrm{~min}$ and the holding cycle with $72^{\circ} \mathrm{C}$ for $7 \mathrm{~min}$. The amplified DNA was electrophoresed on a submerged 1.6 or $2.0 \%$ agarose gel at $50 \mathrm{v}$ for $1.5 \mathrm{~h}$, stained with ethidium bromide and photographed under UV light.

The importance of the concentration of the DNA template used for the amplification was evident. Some failed to produce amplified products with $5 \mathrm{ng} / \mu \mathrm{l}$ templates. When dilutions of $1.0,0.5$ and $0.25 \mathrm{ng} / \mu \mathrm{l}$ of the same sample were tested, they produced consistent RAPDs and consequently $0.5 \mathrm{ng}$ templates were used in this study. The effect of concentration on AP-PCR (i.e. RAPD) has been reported by Welsh \& McClelland. ${ }^{12}$

Data analysis: Twelve random primers(P1,P2,P3,P4,P16,P21,P22,P25,P28,P29, P31 \& P34 maintained at the Plant Germplasm Introduction Laboratory, NIAR) each ten bases in length were selected from a pool of primers that gave reasonable numbers of amplification under the PCR reaction conditions described above. Each cultivar was scored for the presence or absence of reliable amplification product and the data were entered into a symmetrical data matrix. Coefficient of dissimilarity as the \% of mismatched RAPDs were calculated on the basis of the formula ${ }^{13}$ :

$$
\mathrm{D}=1-\left[2 \mathrm{n}_{\mathrm{xy}} /\left(\mathrm{n}_{\mathrm{x}}+\mathrm{n}_{\mathrm{y}}\right)\right]
$$

where $D$ equals the percentage of mismatched fragments between the pair of accession $\mathrm{x}$ and $\mathrm{y}$ and $\mathrm{n}_{\mathrm{xy}}$ represents the matched fragments for both accessions. Cluster analysis using UPGMA (unweighted pair group method with averages) 
Cluster analysis using UPGMA (unweighted pair group method with averages) was performed and a dendrogram was constructed. ${ }^{13}$

\section{RESULTS}

In isolating DNA, the modified method served to be more cost and time effective than the mass method. Even though the yield of DNA was a little lower, it did not require freeze drying of material nor larger volumes of samples and reagents. The samples were directly crushed with a small volume of liquid nitrogen into a powder and DNA could be extracted the same day saving 2-3 days of time usually spent on isolation with the original method.

Of the studied species of sub-genus Ceratotropis, isolation was easier with accessions of azuki bean group but accessions from the mungbean subgroup were not amicable with isolation. They either yielded no DNA at all or only minute amounts of fragmentized DNA. The modified isolation method improved the situation and it yielded DNA even from the above difficult species. However, many accessions of them produced poor results at amplification and as a result all the accessions could not be included in RAPD analysis. Thus differences between azuki and mungbean groups were indicated even at the stages of DNA isolation and amplification. Since some of the accessions yielded pigmented DNA, necessity of further purification is suggested.

Altogether 12 random primers were attempted and data on 8 repeatable and persistent primed events were taken into consideration; two of the primers, $\mathrm{P} 4$ \& P29, produced no amplification. The screening of 8 decamer primers against 24 accessions of Vigna resulted in the amplification of discernible DNA fragments ranging from 2500 to $100 \mathrm{bp}$. The bands beyond this range which were neither prominent nor consistent were not considered in the statistical analysis. This resulted in an average of 6.5 fragments per primer. The size of amplified DNA was measured in comparison with Lambda-DNA digested with Hind-III and Pst-I restricion enzymes.

An example of a typical analysis is illustrated in Fig. 1. Oligonuleotide P1 primed the amplification of 6 fragments of which 5 were polymorphic and 1 is shared by all the accessions.

\section{DISCUSSION}

RAPDs have become useful in determining relationships among various taxa and have been successfully deployed in studying polymorphism in wheat, ${ }^{14}$ elucidating phylogenetics of cereals, ${ }^{15}$ identifying accessions of rice, ${ }^{16}$ determining parentage of maize $\mathrm{e}^{12}$ and tracing resistant gene markers in Phaseolus. ${ }^{17}$ 

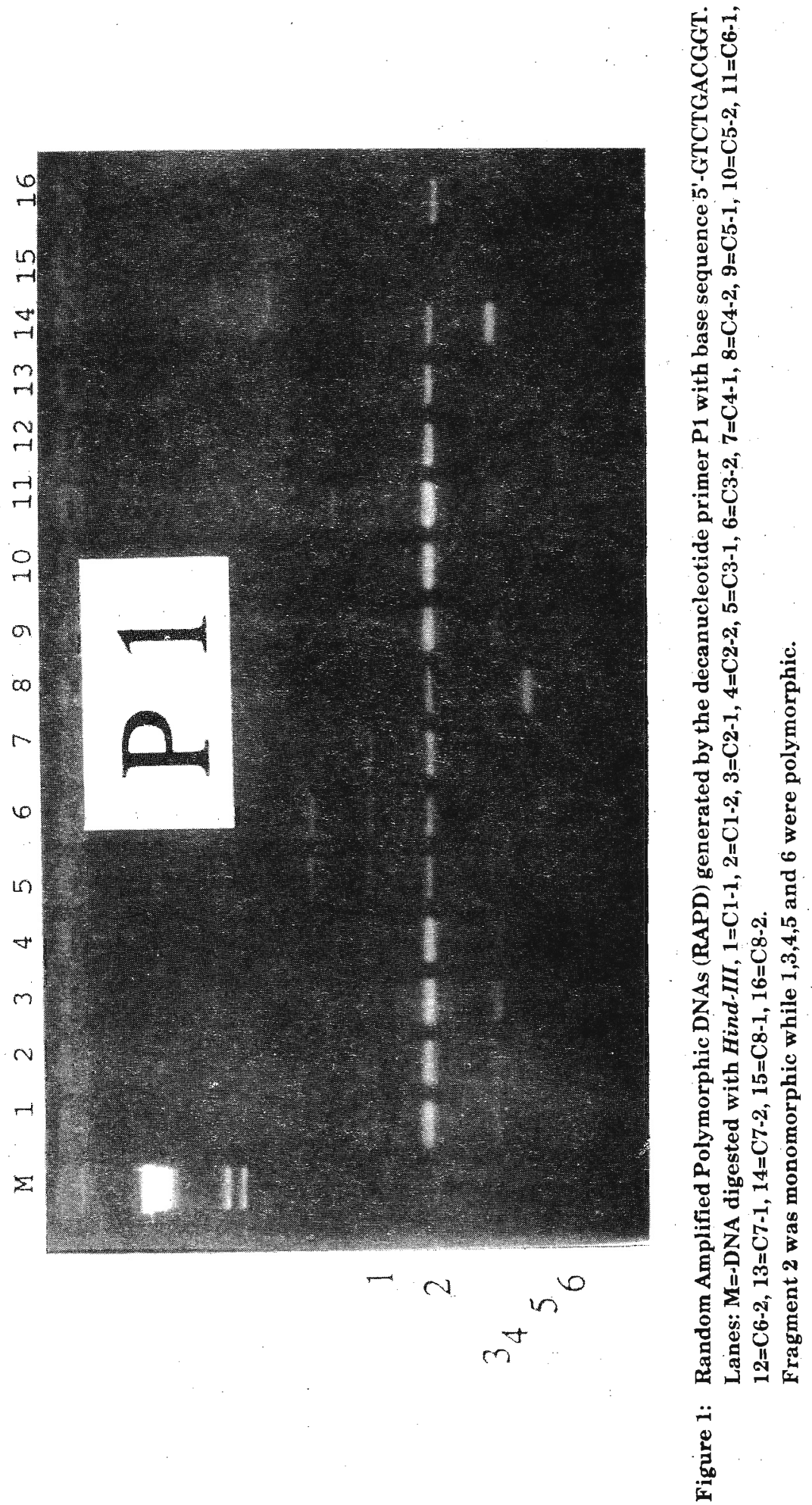
In the present study, a total of 52 RAPDs were recorded from the PCR experiments. Only one fragment of the P1 primer was monomorphic among all the accessions and, therefore almost all the observed amplification fragments were phylogenetically important and could be deployed in generating a cladogram.

The cluster analysis produced two major clusters at $70 \%$ dissimilarity level representing the azuki and mungbean groups (Fig. 2). The larger cluster with less divergence at $62 \%$ level consists of most of the studied species which belong to the hypogeal germination type. The separation of the 2 groups has been reported by RFLP analysis ${ }^{18}$ and differences in carbohydrate composition. ${ }^{19}$

\footnotetext{
$V$. angularis var. angularis

$V$. angularis var. nipponersis

$V$. unibellata var. umbellata

$V$ umbellata var. gracilis

$V$. riukiuensis

is

V. natiashimae

is

V. mininia var. niminia

V. minima subsp. gracilis

$V$. nepalzusis

v. Irinervia

๓

$-$

-

$V$. refleza-pilosa

V. glabrescens

unidentified species

V. umbellato

V. minima subsp. gracilis

V. radiata var. sublobala

$V$. mungo var. mungo

$V$. mungo var. silvestris

$V$. grandiflora
}

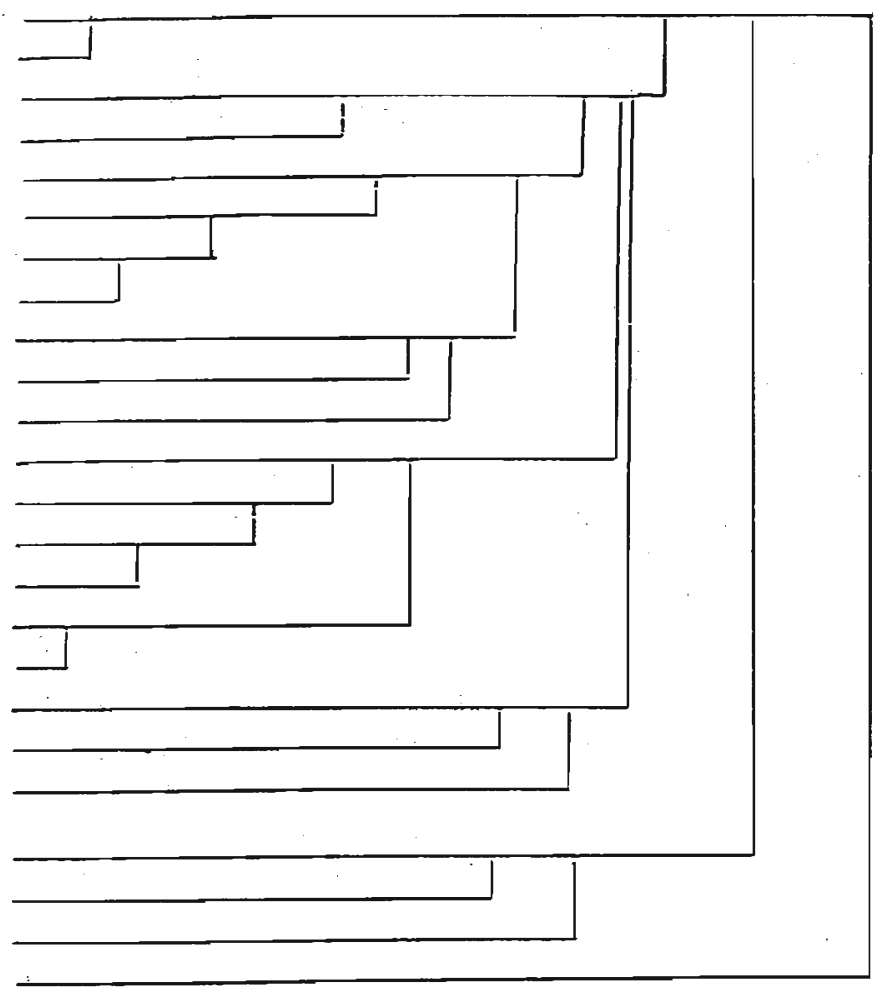

0

40

Dissimilarity Coefficient-\%.

Figure 2: Dendrogram depicting the phylogenetic relationships of the 24 accessions of the Ceratotropis sub-genus: 
Of the accessions, the closest pair was $V$. reflexo-pilosa and $V$. glabrescens which show more than $96 \%$ of similarity. This supports the hypothesis that $V$. reflexo-pilosa is the putative ancestor of $V$. glabrescens. In the group, both of them are unique being the only tetraploids with $2 \mathrm{n}=4 \mathrm{x}=44$, and successful crosses have been obtained between the two species implying the homogeneity of the two genomes. The next most closely related pair was the two varieties angularis and nipponensis of $V$. angularis as is expected. The pair forms a mini cluster with the two varieties of $V$. umbellata at a higher diverging point. The relative position of $V$. angularis and $V$. umbellata in azuki cluster and of $V$. mungo and $V$. radiata in the mungbean cluster is in good agreement with RFLP results. ${ }^{18}$ The isolation of the four accessions of $V$.trinervia into a common cluster at $31 \%$ level indicates their closeness to each other although three are from Malaysia and the fourth is from Thailand. This mini cluster identifies $V$. reflexo-pilosa and $V$. glabrescens pair as their closest relatives. However, placement of $V$. trinervia in the middle of the major cluster contradicts the belief that V.trinervia is intermediary between mungbean and azuki groups. The unidentified species, C9-1, exhibits congruity to wild $V$. umbellata, but the distant separation of wild $V$. umbellata from its cultivated counterparts and of C8-2 from other $V$. trinervia relatives is inexplicable.

The four members of the mungbean group show more divergence among themselves than their counterparts in the azuki bean group. Similar findings have been reported. ${ }^{5} V$. grandiflora was the most divergent indivdual of all. Since it failed to produce AP-PCR with several primers, its position in relation to the others is not reliable.

In the present study only four accessions of the mungbean group could be included due to the inability of many others to produce RAPDs. The failure may have been caused by two factors. Either they require conditions and time periods for PCR different from the conditions which were suitable with azuki members. Or it may be due to some contaminants still remaining in the template even after attempts of re-purification of DNA which inhibt DNA from amplifying. Therefore different means of DNA isolation and more conducive conditions in PCR is suggested for the mungbean group.

RAPD is a much faster and more convenient method in the detection of polymorphism than the traditional RFLP analysis. RAPD data can be obtained within $2 \mathrm{~h}$ after PCR as opposed to the Southern Blotting and DNA hybridization required in RFLP. Further it does not require specific base sequences identified by restriction endonucleases and thus any arbitrary sequences can be utilized. The linkage between RAPDs with RFLP and isozyme markers has been established in legumes ${ }^{20}$ and consequently RAPD in association with the latter would provide faster methods in gene mapping. Therefore the results presented here show promise first in employing them in biodiversity and germplasm evaluation and then in breeding programmes of Vigna species. 


\section{Acknowledgement}

I thank the Japan International Cooperation Agency for providing me with the financial assistance to conduct this research at the National Institute of Agrobiological Resources in Japan.

\section{References}

1. Verdcourt B. (1970). Studies in the Leguminosae-Pappilionoideae for the flora of tropical East Africa. Part 4. Kew Bulletin 24: 507-569.

2. Mare'chal R., Maschepa J.M. \& Stainer F. (1978). Etude taxonomique d'un groupe complex d'especes des generes Phaseolus et Vigna (Papilionaceae) sur la base de donnees morphologiques et polliniques, traitees par l'analyse informatique. Biossiera 28: 208-217.

3. Maekawa F. (1955). Topo-morphological and taxonomical studies in Phasioleae, Leguminosae. Japanese Journal of Botany 15: 103-116.

4. Egawa Y., Siriwardhane D., Tomooka N., Tomita K. \& Nakano H. (1990). Collection of $V$. riukiuensis and reflexo-pilosa, wild relatives of azuki bean on Iriomote Island, Okinawa prefecture. Plant Genetic Resources Exploration 6: 23-30.

5. Egawa Y., Bujang I., Anthonysamy S. \& Tomooka N. (1992). Genetic variation of wild Vigna species collected from Peninsular Malaysia detected from isozyme analysis. Japanese Journal of Breeding 42 (Suppl.2): 570-571.

6. Tomooka N., Lairungreang C., Nakeeraks P., Egawa Y. \& Thavarasook C. (1991). Mungbean and the genetic resources: the final report submitted to the National Research Council of Thailand and Tropical Agricultural Research Center, Japan.

7. Tomooka N., Egawa Y., Lairungreang C. \& Thavasook C. (1992). Collection of wild Ceratotropis species on the Nansei Archipelago, Japan and evaluation of bruchid resistance. Japanese Agricultural Research Quarterly 26(30): 222-230.

8. Murray T. \& Thompson J.L. (1980). Rapid isolation of high molecular weight plant DNA. Nucleic Acids Research 8: 4321-4325.

9. Doyle J.J. \& Doyle J.L. (1987). A rapid DNA isolation procedure for small quantities of fresh leaf tissue. Phytochemical Bulletin 19: 11-15. 
10. Sambrook J., Fritsch E.F. \& Maniatis T. (1989). Molecular cloning: $a$ laboratory manual. (2nd ed) Cold Spring Harbor Laboratory, New York.

11. Williams J.G.K., Kubelik A.R., Livak K.J., Rafalski J.A. \& Tingey S.V. (1990). DNA polymorphism amplified by arbitrary primers are useful as genetic markers. Nucleic Acid Research 18: 6531-6535.

12. Welsh J. \& McClelland M. (1990). Fingerprinting genomes using PCR with arbitrary primers. Nucleic Acid Research 18: 7213-7218.

13. Sneath P.H.A \& Sokal R.R. (1973). Numerical taxonomy. W.H. Freeman \& Co., San Francisco. 573 pp.

14. Vierling R.A. \& Nguyen H.T. (1992). Use of RAPD markers to determine the genetic diversity of diploid genotypes. Theoretical and Applied Genetics 84: 835-838.

15. Weining S. \& Langridge P. (1991). Identification and mapping of polymorphism in cereals based on the polymerase chain reaction. Theoretical and Applied Genetics 82: 209-216.

16. Fukuoka S, Hosaka K. \& Kamijima O. (1992). Use of random amplified DNAs (RAPDs) for identification of rice accessions. Japanese Journal of Genetics 67: 243-252.

17. Haley S.D., Miklas P.N., Stavely J.R., Byrum J. \& Kelly J.D. (1993). Identification of RAPD markers linked to a major rust resistance gene block in common bean. Theoretical and Applied Genetics 86: 505-512.

18. Fatokun C.A., Danesh D., Young N.D \& Stewart E.L. (1993). Molecular taxonomic relationships in the genus Vigna based on RFLP analysis. Theoretical and Applied Genetics 86: 97-104.

19. Yasui T., Tateishi Y. \& Ohashi H. (1985). Distribution of low molecular weight carbohydrates in the genus Ceratotropis of the genus Vigna (Leguminosae). Botanical Magazine of Tokyo 98: 75-87.

20. Torres A.M., Weeden N.F. \& Martin A. (1993). Linkage among Isozyme, RFLP and RAPD markers in Vicia faba. Theoretical and Applied Genetics 85: 937-945. 